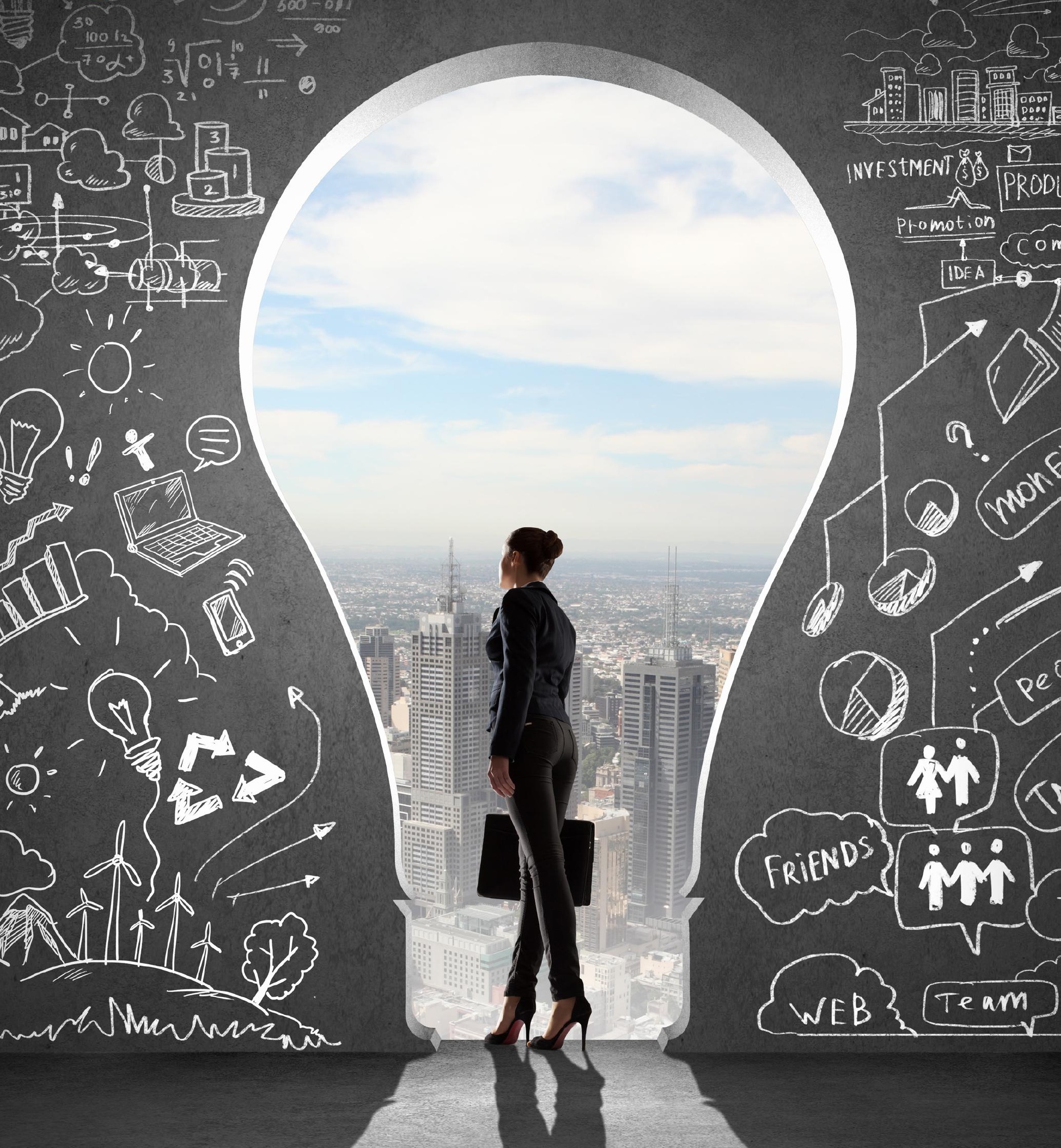




\section{OS MODELOS DE NEGÓCIOS DO FUTURO}

| POR JIMMY GREER

\section{Um guia para monitorar e aproveitar os novos tipos de valor que estão sendo criados.}

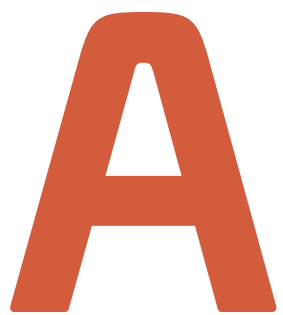

tualmente, surgem oportunidades e, ao mesmo tempo, crescem os desafios que afetam a capacidade de as pessoas prosperarem. Nesse contexto, novos modelos de negócios podem propor referências para que as economias e as sociedades enfrentem os obstáculos e floresçam.

Os modelos de negócios recentemente foram promovidos de um exercício puramente de "modelagem" para uma reavaliação completa da proposição, criação e percepção de valor do negócio, e isso ocorreu por várias razões. É claro que a tecnologia abriu caminho para emergirem novos formatos, mas ela é apenas uma peça em uma coleção de impulsionadores para a criação de valor que, quando combinada a outras - como a importância das redes - em uma variedade de contextos - como a classe média em crescimento -, leva à reinvenção dos modelos de negócios.

Cinco principais fatores levaram os modelos de negócios ao centro das atenções de empreendedores e de empresas estabelecidas:

\section{Menos custos tecnológicos, mais ideias}

Barreiras à entrada de concorrentes, como poder de processamento caríssimo e software proprietário, evaporaram.
Isso vem permitindo que uma geração de Davis, armados apenas com suas ideias e limitados recursos financeiros, assumam o lugar de antigos Golias.

\section{Cultura de startups}

Fundar um negócio tornou-se a aspiração de carreira dos tempos atuais, tomando o longo e incontestado reinado do "emprego para a vida toda". E essa nova forma de pensar não pertence apenas aos millennials (nascidos nas décadas de 1980 e 90).

\section{Novas ferramentas}

Uma profusão de ferramentas surgiu para atender ao crescente interesse empreendedor. Por exemplo, o quadro de modelo de negócios (business model canvas) tornou-se o padrão de planejamento para quem aspira abrir uma startup, pois é um mapa pré-formatado que permite traçar ideias e moldar o futuro. A ferramenta estabelece, em uma única folha de papel, nove componentes necessários para iniciar um negócio.

\section{Capital em rede}

O acesso a financiamento tem sido um obstáculo para todas as empresas. Com o crescimento de redes digitalmente mais seguras, indivíduos começam a se unir em diferentes escalas para congregar recursos e financiar oportunidades entre si. 


\section{Mundo em mudança}

Nas últimas décadas, o aumento da renda em países de rendimentos baixos e médios abriu espaço para novos modelos prosperarem. Os modelos tradicionais deixaram a desejar no atendimento de alguns mercados, ao mesmo tempo em que os motores da prosperidade pararam nas economias avançadas, fazendo com que os rendimentos da classe média estagnassem. Assim, meios mais inteligentes e equitativos de criação de valor, que produzam menos desperdício e sejam mais responsivos às novas demandas, estão sendo incorporados nas práticas de negócios.

\section{MODELOS DE NEGÓCIOS DO FUTURO}

A seguir, destacamos cinco modelos dignos de exploração em mais profundidade, os quais abrangem áreas que têm o potencial de alterar a forma como as pessoas vivem e trabalham. Alguns já deram origem a negócios de bilhões de dólares e se tornaram familiares; outros começaram a atender às necessidades dos clientes em nichos mais modestos, mas com capacidade de criar valor e se tornar valiosos.

\section{Plataformas}

O modelo baseia-se em plataformas que reúnem virtualmente compradores e vendedores, seja em mercados bilaterais ou multilaterais. Os donos das plataformas normalmente recebem uma taxa de seus usuários. É um tipo de negócio que atende a comunidades e clientes específicos e que, na maioria dos casos, beneficia-se de efeitos de escala e de rede.

\section{Customização de massa 2.0}

Até pouco tempo, as cadeias de suprimento globais sincronizavam-se para fabricar um produto e entregá-lo na porta do cliente. Agora, o modelo "sob demanda" substitui o "em estoque". Esse modelo tende a se tornar dominante com o acesso crescente a hardwares de baixo custo, como as impressoras 3D; com a erupção da cultura "faça você mesmo"; e a preferência do artesanato e das experiências em relação ao consumismo do mercado de massa passivo e de tamanho único.

\section{Frugal}

O termo frugal originou-se em economias de custo e renda mais baixa - jugaad na Índia, ou "gambiarra" no Brasil, países onde a falta de recursos leva as pessoas a usarem sua engenhosidade e o que têm à mão para resolver os problemas. Esse modo de pensar está profundamente entrelaçado nos modelos de negócios de algumas das maiores empresas do mundo. Corporações frugais podem responder às demandas dos clientes por produtos e serviços acessíveis e de alta qualidade, além de criar segmentos completamente novos de mercado.

\section{Troca moderna}

Trocar bens ou habilidades com outras pessoas em vez de pagar por algo. Usar moedas digitais e alternativas para transacionar, no lugar de dinheiro que corre no sistema controlado pelo Banco Central. Esses são dois exemplos de um modelo de negócio em ascensão que emerge tanto do acesso mais amplo às ferramentas digitais quanto em resposta às

\section{NÚMERO DE USUÁRIOS DE INTERNET POR REGIÃO}

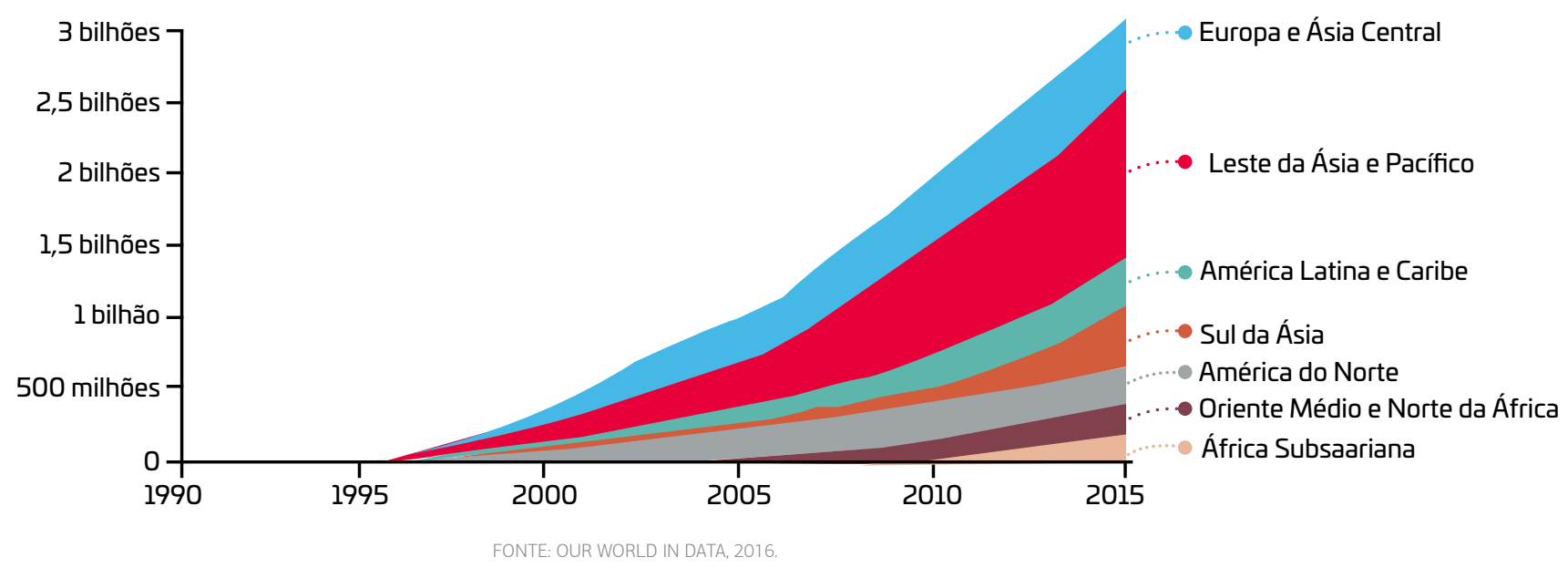


mudanças das circunstâncias econômicas. Essa "economia de compartilhamento" traz benefícios como a capacidade de ter acesso a produtos e serviços sem afetar as finanças pessoais e domésticas e a construção do senso de comunidade.

\section{Pague o que quiser}

Os clientes pagam o quanto querem por um produto ou serviço: de zero a um valor que exceda o preço desejado pelo vendedor. A rentabilidade desse modelo baseia-se na capacidade de atrair novos clientes com desejo de se tornarem parte do sucesso do negócio. O sistema "pague o que quiser" pode ser empregado em fóruns digitais como parte de um modelo freemium, ou baseado em níveis, em que uma versão básica é oferecida gratuitamente, mas subsidiada por uma versão premium, com recursos adicionais pagos.

\section{Mega-hiperlocal}

Os negócios hiperlocais de primeira geração são, em geral, serviços de entrega ou de utilidade doméstica. Já na segunda geração, os componentes de um produto ou serviço passam a ser (parcial ou totalmente) fornecidos e montados na mesma área geográfica em que são vendidos. Os negócios mega-hiperlocais são capazes de criar marcas com identidade local, construir ecossistemas de oportunidades econômicas da localidade, cultivar fortes relações pessoais com os clientes, melhorar a qualidade de vida do bairro e ter baixo impacto ambiental.

Esses modelos, ou a combinação de seus elementos, tendem a direcionar a maneira como as pessoas vivem e trabalham. Muitos deles se sobrepõem, com elementos de uns presentes em outros. Estamos testemunhando a emergência de uma cultura "instale e use" (plug and play), em que os recursos disponíveis podem ser combinados para criar soluções híbridas que se aplicam a oportunidades específicas para atender às necessidades dos clientes no século XXI.

\section{TEMAS SUBJACENTES}

Uma série de temas nascentes, se bem compreendidos, pode equipar empresas e governos com habilidades, ferramentas e capacidade de compreensão para lidarem com os próximos desafios e se engajarem com novos modelos de negócios. Os cinco principais aspectos que merecem atenção são:

\section{Juntos}

Caminhar sozinho não é mais uma opção. Do digital ao físico, na fabricação baseada na nuvem ou nos negócios mega-hiperlocais, são os ecossistemas compostos de pessoas, recursos e ferramentas que, na maioria dos casos, fazem a diferença e proporcionam o potencial para prosperar.

\section{Trabalhar melhor}

À medida que muda a maneira como as pessoas trabalham, surgem novas questões. Um futuro melhor para o trabalho baseado em plataformas é mais partilhado, com lucros distribuídos de forma mais uniforme entre os participantes e com decisões alcançadas coletivamente.

\section{Utilização sustentável de recursos}

Ter relacionamento com recursos que não são extrativos e gerar retornos positivos serão dois fatores que guiarão as empresas para a criação de valor sustentável a longo prazo. As organizações precisarão melhorar a sua compreensão dos diferentes agentes envolvidos (stakeholders) e expandir suas avaliações de materialidade para englobar vários tipos de capital (financeiro, social, ambiental, etc).

\section{Apoio à experimentação e ao crescimento}

Os seis modelos delineados neste artigo compartilham elementos entre si e podem ser utilizados simultaneamente para diferentes produtos ou serviços no mesmo negócio. É o caso de uma plataforma que pode ser usada em uma customização de massa 2.0 e empregar a estrutura de preços "pague o que quiser". Seria muito positivo se formuladores de políticas criassem meios para apoiar usos múltiplos e híbridos desses modelos e formas de experimentação mais amplas sem temor de consequências comerciais adversas.

\section{Colaboração e crescimento}

Grandes e pequenos negócios podem ganhar ao colaborar para que novos modelos de negócios surjam. As startups têm a oportunidade de acessar ferramentas para ganhar escala, e as empresas maiores beneficiam-se com as inovações e a mentalidade empreendedora de seus colaboradores.

Esses temas exigirão lideranças hábeis. As capacidades técnicas e estratégicas dos futuros líderes empresariais deverão ir dos pré-requisitos de alfabetização digital e pensamento computacional à compreensão dos desafios regulatórios, além da capacidade de monitorar, capturar e relatar os novos tipos de valor que estão sendo criados.

É certo que os modelos de negócios do futuro demandam ações no presente. PARA SABER MAIS:
- Jimmy Greer. Business models of the future: emerging value creation. Association of
Chartered Certified Accountants (ACCA), 2017. Disponivel em: goo.gl/FJUEsX
- Julia Murphy e Max Roser. Internet. Our world in data, 2016. Disponivel em: goo.gl/n3nE

JIMMY GREER > Chefe de Sustentabilidade e Professional Insights da Association of Chartered Certified Accountants (ACCA) > jimmy.greer@accaglobal.com 